\title{
Heat and Mass Transfer on MHD Boundary Layer Flow through porous medium over a vertical plate
}

\author{
G. Manohar ${ }^{1}$, S.V.Suneetha ${ }^{2}$ and R.Siva Prasad $^{3}$ \\ ${ }^{I}$ Research Scholar, Department of Mathematics, SriKrishnadevaraya University, Ananthapur, A. Pradesh, India \\ ${ }^{2}$ Assistant Professor, Department of Mathematics, Rayalseema Univbersity, Kurnool, Andhra Pradesh, India \\ ${ }^{3}$ Professor, Department of Mathematics, SriKrishnadevaraya University, Ananthapur, Andhra Pradesh, India
}

\begin{abstract}
We have considered the hydro magnetic boundary layer flow with heat and mass transfer over a vertical plate in the presence of magnetic field with Soret and Dufour effects, chemical reaction and a convective heat exchange at the surface with the surrounding has been studied. The similarity solution is used to transform the system of partial differential equations and an efficient numerical technique is implemented to solve the reduced system by using the Runge-Kutta fourth order method with shooting technique. A comparison study with the previous results shows a very good agreement. The results are presented graphically and the conclusion is drawn that the flow field and other quantities of physical interest are significantly influenced by these parameters.
\end{abstract}

Keywords: vertical plate, convective boundary condition, chemical reaction, heat and mass transfer, magnetic field, similarity solution

\section{Introduction}

Heat transfer and mass transfer are kinetic processes that may occur and be studied separately or jointly. Studying them apart is simpler, but both processes are modelled by similar mathematical equations in the case of diffusion and convection (there is no mass-transfer similarity to heat radiation), and it is thus more efficient to consider them jointly. Besides, heat and mass transfer must be jointly considered in some cases like evaporative cooling and ablation. The usual way to make the best of both approaches is to first consider heat transfer without mass transfer, and present at a later stage a briefing of similarities and differences between heat transfer and mass transfer, with some specific examples of mass transfer applications. Following that procedure, we forget for the moment about mass transfer (dealt with separately under Mass Transfer), and concentrate on the simpler problem of heat transfer. There are complex problems where heat and mass transfer processes are combined with chemical reactions, as in combustion; but many times the chemical process is so fast or so slow that it can be decoupled and considered apart, as in the important diffusion-controlled combustion problems of gas-fuel jets, and condensed fuels (drops and particles), which are covered under Combustion kinetics.

Magneto-hydrodynamic (MHD) boundary layers with heat and mass transfer over a flat surface are found in a many engineering and geophysical applications such as geothermal reservoirs, thermal insulation, cooling of nuclear reactors. Many chemical engineering processes like metallurgical and polymer extrusion processes involve cooling of a molten liquid being stretched into a cooling system; the fluid mechanical properties of the penultimate product depend mainly on the cooling liquid used and the rate of stretching. Some polymer fluids like Polyethylene oxide and polysobutylene solution in cetane, having batter electromagnetic properties, are normally used as cooling liquid as their flow can be regulated by external magnetic fields in order to improve the quality of the final product. Bejan and Khair [3] investigated the free convection boundary layer flow in a porous medium owing to combined heat and mass transfer. Lai and Kulacki [9] used the series expansion method to investigate coupled heat and mass transfer in natural convection from a sphere in a porous medium. The suction and blowing effects on free convection coupled heat and mass transfer over a verrtical plate in a saturated porous medium were studied by Raptis et al. [15] and Lai and Kulacki [10] respectively. The effect of thermal radiation on heat and mass transfer flow of a variable viscosity fluid past a vertical porous plate permeated by a transverse magnetic field was reported in Makinde and Ogulu[12]. Mikinde [11] studied the similarity solution of hydromagnetic heat and mass transfer over a vertical plate with a convective surface boundary condition. The paper demonstrates that a similarity solution is possible if the convective heat transfer associated with the hot fluid on the lower surface of the plate is proportional to the inverse square root of the axial distance. Recently Gnaneswar Reddy and Bhaskar Reddy[6] reported a Soret and Dufour effects on steady MHD free convection flow past a semi-infinite moving vertical plate in a porous medium with viscous dissipation. In all these studies Soret / Dufour effects are assumed to be negligible. Such effects are significant when density differences exist in the flow regime. For example when species are introduced at a surface in fluid domain, with different (lower) density than the surrounding fluid, both Soret and Dufour effects can be significant. Also, when heat and mass transfer occur simultaneously in a moving fluid, the relations between the 
fluxes and the driving potentials are of more intricate nature. It has been found that an energy flux can be generated not only by temperature gradients but by composition gradients as well. The energy flux caused by a composition gradient is called the Dufour or diffusion-thermo effect. On the other hand, mass fluxes can also be created by temperature gradients and this is called the Soret or thermal-diffusion effect. The thermal-diffusion (Soret) effect, for instance, has been utilized for isotope separation, and in mixture between gases with very light molecular weight $(\mathrm{H} 2, \mathrm{He})$ and of medium molecular weight (N2, air), the diffusion-thermo (Dufour) effect was found to be of a considerable magnitude such that it can not be ignored (Eckert and Drake [4]). In view of the importance of these above mentioned effects, Dursunkaya and Worek [4] studied diffusion-thermo and thermaldiffusion effects in transient and steady natural convection from a vertical surface, whereas Kafoussias and Williams [8] presented the same effects on mixed free-forced convective and mass transfer boundary layer flow with temperature dependent viscosity. Recently, Anghel et al. [2] investigated the Dufour and Soret effects on free convection boundary layer flow over a vertical surface embedded in a porous medium. Very recently, Postelnicu [14] studied numerically the influence of a magnetic field on heat and mass transfer by natural convection from vertical surfaces in porous media considering Soret and Dufour effects. Alam et al [1] have investigated the Dufour and Soret Effects on Unsteady MHD Free Convection and Mass Transfer Flow past a Vertical Porous Plate in a Porous Medium. Shariful Alam et al [16] has presented the Local Similarity Solutions for Unsteady MHD free Convection and Mass Transfer Flow Past an Impulsively Started Vertical Porous Plate with Dufour and Soret Effects. The Dufour and Soret effects on unsteady MHD Convective Heat and Mass Transfer Flow due to a Rotating Disk was analyzed by Maleque [13]. However, the interaction of Soret and Dufour effects on steady MHD free convection flow in a porous medium with viscous dissipation has received a little attention. Hence, the object of the present chapter is to analyze Soret and Dufour Effects on Similarity solution of hydro magnetic heat and mass transfer over a vertical plate with a convective surface boundary condition and chemical reaction. The governing equations are transformed by using similarity transformation and the resultant dimensionless equations are solved numerically using the Runge-Kutta method with shooting technique. The effects of various governing parameters on the velocity, temperature, concentration, skin-friction coefficient, Nusselt number and Sherwood number are shown in figures and tables and analyzed in detail.

\section{Formulation And Solution Of The Problem:}

Let us consider a steady, laminar, hydro magnetic coupled heat and mass transfer by mixed convection flow over a vertical plate. The fluid is assumed to be Newtonian, electrically conducting and its property variations due to temperature and chemical species concentration are limited to fluid density. The density variation and the effects of the buoyancy are taken into account in the momentum equation (Boussinesq's approximation). In addition, there is no applied electric field and all of the Hall effects and Joule heating are neglected. Since the magnetic Reynolds number is very small for mast fluid used in industrial applications, we assumed that the induced magnetic field is negligible. The physical configuration of the problem is as shown in Figure 1.

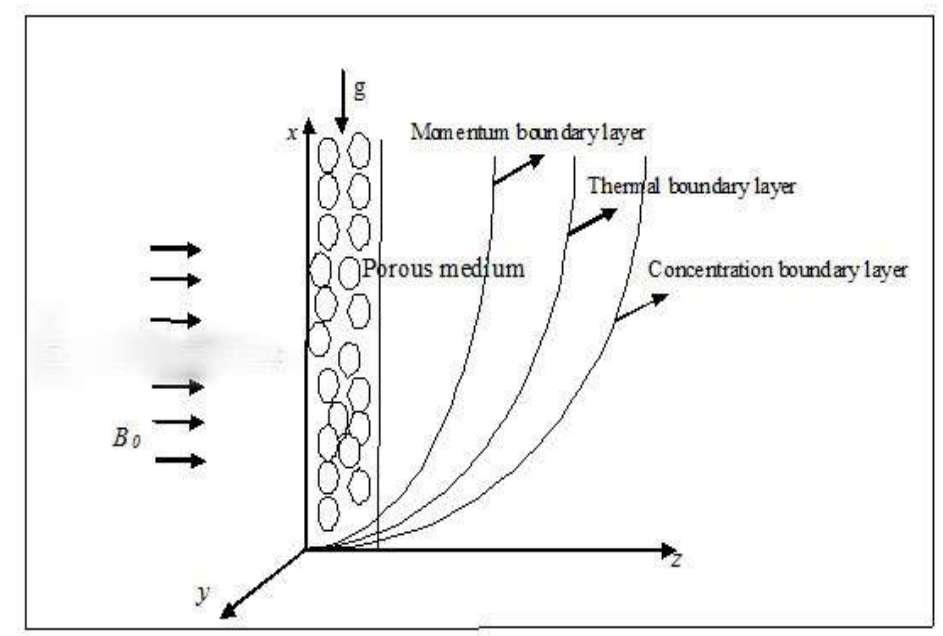

Figure 1: Physical configuration of the problem

Let the $\mathrm{x}$-axis be taken along the direction of plate and y-axis normal to it. If $u, v, T$ and $C$ are the fluid $x$-component of velocity, $y$-component of velocity, temperature and concentration respectively, then under the Boussinesq and boundary-layer approximations, the governing equations for this problem con be written as: 
$\frac{\partial u}{\partial x}+\frac{\partial v}{\partial y}=0$

$u \frac{\partial u}{\partial x}+v \frac{\partial u}{\partial y}=v \frac{\partial^{2} u}{\partial y^{2}}-\frac{\sigma B_{0}^{2}}{\rho}\left(u-U_{\infty}\right)+g \beta_{T}\left(T-T_{\infty}\right)+g \beta_{c}\left(C-C_{\infty}\right)$

$u \frac{\partial T}{\partial x}+v \frac{\partial T}{\partial y}=\alpha \frac{\partial^{2} T}{\partial y^{2}}+\frac{D_{m} k_{T}}{c_{s} c_{p}} \frac{\partial^{2} C}{\partial y^{2}}+\frac{v}{c_{p}}\left(\frac{\partial u}{\partial y}\right)^{2}$

$u \frac{\partial C}{\partial x}+v \frac{\partial C}{\partial y}=D_{m} \frac{\partial^{2} C}{\partial y^{2}}+\frac{D_{m} k_{T}}{T_{m}} \frac{\partial^{2} T}{\partial y^{2}}+k r^{2}\left(C-C_{\infty}\right)$

The boundary conditions at the plate surface and for into the cold fluid may be written as

$$
\begin{aligned}
& u(x, 0)=v(x, 0)=0,-\kappa \frac{\partial T}{\partial y}(x, 0)=h\left[T-T_{w}(x, 0)\right], C_{w}(x, 0)=A x^{\lambda}+C_{\infty}, \\
& u(x, \infty)=U_{\infty}, T(x, \infty)=T_{\infty}, C(x, \infty)=C_{\infty}, \\
& u(x, \infty)=U_{\infty}, T(x, \infty)=T_{\infty}, C(x, \infty)=C_{\infty} .
\end{aligned}
$$

The velocity components $u$ and $v$ are respectively obtained as follows:

$u=\frac{\partial \psi}{\partial \bar{y}}, v=-\frac{\partial \psi}{\partial \bar{x}}$.

A similarity solution of Equations (1)-(6) is obtained by defying an independent variable $\eta$ and a dependent variable 'f ' in terms of the stream function $\Psi$ as

$\eta=y \sqrt{\frac{U_{\infty}}{v x}}, \quad \psi=\sqrt{v x U_{\infty}} f(\eta)$.

The dimensionless temperature and concentration are given as

$\theta(\eta)=\frac{T-T_{\infty}}{T_{w}-T_{\infty}}, \phi(\eta)=\frac{C-C_{\infty}}{C_{w}-C_{\infty}}$

Where $T_{w}$ is the temperature of the hot fluid at the left surface of the plate. Substituting the equations (6)-(8) in to Equations (1)-(5), we obtain

$$
\begin{aligned}
& f^{\prime \prime \prime}+\frac{1}{2} f f^{\prime \prime}-H a\left(f^{\prime}-1\right)+G r \theta+G c \phi=0 \\
& \theta^{\prime \prime}+\frac{1}{2} \operatorname{Pr} f \theta^{\prime}+\frac{1}{2} \operatorname{Pr} D u \phi^{\prime \prime}+\frac{1}{2} \operatorname{Pr} E c f^{\prime 2}=0 \\
& \phi^{\prime \prime}+\frac{1}{2} S c f \phi^{\prime}+\frac{1}{2} S c S r \theta^{\prime \prime}-\kappa r^{2} S c \phi=0 \\
& f(0)=0, f^{\prime}(0)=0, \theta^{\prime}(0)=B i[\theta(0)-1], \phi(0)=0 \\
& f^{\prime}(\infty)=1, \theta(\infty)=\phi(\infty)=0 .
\end{aligned}
$$

Where the prime symbol represents the derivative with respect to $\eta$

Where, $H a=\sigma B_{0}^{2} x / \rho U_{\infty}$ is Magnetic field parameter (Hartmann number), $G r=\left(g \beta_{T}\left(T_{w}-T_{\infty}\right) x\right) / U_{\infty}{ }^{2}$ is the Thermal Grashof number, $G c=\left(g \beta_{c}\left(C_{w}-C_{\infty}\right) x\right) / U_{\infty}^{2}$ is the Solutal Grashof number, $D u=\left(D_{m} k_{T}\left(C_{w}-C_{\infty}\right)\right) /\left(c_{s} c_{p}\left(T_{w}-T_{\infty}\right)\right)$ is Dufour number, $S r=\left(D_{m} k_{T}\left(T_{w}-T_{\infty}\right)\right) /\left(v T_{m}\left(C_{w}-C_{\infty}\right)\right)$ is Soret number, $\quad E c=\left(U_{\infty}^{2} / c_{p}\left(T_{w}-T_{\infty}\right)\right)$ is Eckert number, $B i=(h / k) \sqrt{v x / U_{\infty}}$ is Convective heat transfer parameter, $\operatorname{Pr}=v / \alpha$ is Prandtl number, $S c=v / D_{m}$ is Schmidt number, $K r=\kappa r^{2} 2 x / U_{\infty}$ is Chemical reaction rate constant, $\mathrm{Re}=U t / v$ is the Reynolds number

It is noteworthy that the local parameters $B i, H a, G r$ and $G c$ in Equations (9)-(13) are functions of x. However, in order to have a similarity solution all the parameters $\mathrm{Bi}, \mathrm{Ha}, \mathrm{Gr}, \mathrm{Gc}$, Du, $\mathrm{Sr}$, Ec must be constant and we therefore assume

$h=c x^{-\frac{1}{2}}, \sigma=a x^{-1}, \beta_{T}=b x^{-1}$ and $\beta_{c}=d x^{-1}$ 
Where $a, b, c, d$ are constants, Other physical quantities of interest in this problem such as the skin friction parameter $C_{f}=2(\operatorname{Re})^{-\frac{1}{2}} f^{\prime \prime}(0)$, the plate surface temperature $\theta(0)$, Nusselt number $N u=-(\operatorname{Re})^{\frac{1}{2}} \theta^{\prime}(0)$ and the Sherwood number $S h=-(\operatorname{Re})^{\frac{1}{2}} \phi^{\prime}(0)$ can be easily computed. For local similarity case, integration over the entire plate is necessary to obtain the total skin friction, total heat and mass transfer rate. The set of coupled nonlinear governing boundary layer equations (9)-(11) together with the boundary conditions (12\&13) are solved numerically by using the Runge-Kutta fourth order technique along with shooting method. First of all, higher order non-linear differential Equations (9)-(11) are converted into simultaneous linear differential equations of first order and they are further transformed into initial value problem by applying the shooting technique (Jain $e t$ al.[7]). The resultant initial value problem is solved by employing Runge-Kutta fourth order technique. The step size $\Delta \eta=0.05$ is used to obtain the numerical solution with decimal place accuracy as the criterion of convergence. From the process of numerical computation, the skin-friction coefficient, the Nusselt number and the Sherwood number, which are respectively proportional to $f^{\prime \prime}(0),-\theta^{\prime}(0)$ and $-\phi^{\prime}(0)$, are also sorted out and their numerical values are presented in a tabular form.

\section{Results And Discussions}

Numerical results are reported in the tables $1-2$. The prandtl number was taken to be $\mathrm{Pr}=0.72$ which corresponds to air, the value of Schmidt number $(\mathrm{Sc})$ were chosen to be $\mathrm{Sc}=0.24,0.62,0.78,2.62$, representing diffusing chemical species of most common interest in air like $\mathrm{H}_{2}, \mathrm{H}_{2} \mathrm{O}, \mathrm{NH}_{3}$ and Propyl Benzene respectively. Attention is focused on positive value of the buoyancy parameters that is, Grashof number Gr>0(which corresponds to the cooling problem)and solutal Grashof number $\mathrm{Gc}>0$ (which indicates that the chemical species concentration in the free stream region is less then the concentration at the boundary surface).In order to benchmark our numerical results, we have compared the plate surface temperature $\theta(0)$ and the local heat transfer rate at the plate surface $\theta^{\prime}(0)$ in the absence of both magnetic field and buoyancy forces for various values of $B i$ with those of Gnaneswar Reddy and Bhaskar Reddy [6] and found them in excellent agreement as demonstrated in table 1.From table 2, it is important to note that the local skin friction together with the local heat and mass transfer rate at the plate surface increases with increasing intensity of buoyancy forces $(\mathrm{Gr}, \mathrm{Gc})$, magnetic field $(\mathrm{Ha})$, convective heat change parameter (Bi), Eckert number ( $\mathrm{Ec}$ ), Dufour number $(\mathrm{Du})$ and Soret number $(\mathrm{Sr})$. However, an increase in the Schmidt number $(\mathrm{Sc})$ and chemical parameter $(\kappa r)$ causes a decrease in both skin friction and surface heat transfer rate and an increase in the surface mass transfer rate.

The effects of various parameters on velocity profiles in the boundary layer are depicted in Figures 1-9. It is observed from Figures 1-9, that the velocity starts from a zero value at the plate surface and increase to the free stream value far away from the plate surface satisfying the far field boundary condition for all parameter values. In Figure 1 the effect of increasing the magnetic field strength on the momentum boundary layer thickness is illustrated. It is now a well established fact that the magnetic field presents a damping effect on the velocity field by creating drag force that opposes the fluid motion, causing the velocity to decease. However, in this case an increase in the $(\mathrm{Ha})$ only slightly slows down the motion of the fluid away from the vertical plate surface towards the free stream velocity, while the fluid velocity near the vertical plate surface increases. Similar trend of slight increase in the fluid velocity near the vertical plate is observed with an increase in convective heat transfer parameter $(B i)$. Figures 3,4,7,8\&9shows the variation of the boundary-layer velocity with the buoyancy forces parameters $(G r, G c)$, Eckert number $(E c)$, Dufour number $(D u)$ and Soret number $(S r)$. In the above cases an upward acceleration of the fluid in the vicinity of the vertical wall is observed with increasing intensity of buoyancy forces. Further downstream of the fluid motion decelerates to the free stream velocity. Figure 5 and 6 shows a slight decrease in the fluid velocity with an increase in the Schmidt number $(S c)$ and chemical reaction parameter $(K r)$.

Generally, the fluid temperature attains its maximum value at the plate surface and decreases exponentially to the free stream zero value away from the plate satisfying the boundary condition. This is observed in Figures 10-19. From these figures, it is interesting to note that the thermal boundary layer thickness decreases with an increase in the intensity of magnetic field $\mathrm{Ha}$, the buoyancy forces $(G r, G c)$, permeability parameter $(P r)$ and Soret number $(S r)$. Moreover, the fluid temperature increases with an increase in the Schmidt number $(S c)$, the convective heat exchange at the plate surface $(B i)$, chemical reaction parameter $(\kappa r)$, Eckert number $(E c)$ and Dufour number $(D u)$ leading to an increase in thermal boundary layer thickness.

Figures 20-27 depict chemical species concentration profiles against span wise coordinate $\eta$ for varying values physical parameters in the boundary layer. The species concentration is highest at the plate surface and decrease to zero far away from the plate satisfying the boundary condition. From these figures, it is noteworthy that the 
concentration boundary layer thickness decreases with an increase in the magnetic field intensity $H a$, the buoyancy forces $(G r, G c)$, Schmidt number $(S c)$, Eckert number $(\mathrm{Ec})$, Dufour number $(\mathrm{Du})$ and chemical reaction parameter $(\kappa r)$ and Moreover, the fluid concentration increases with an increase in the Soret number $(\mathrm{Sr})$ leading to an increase in thermal boundary layer thickness.

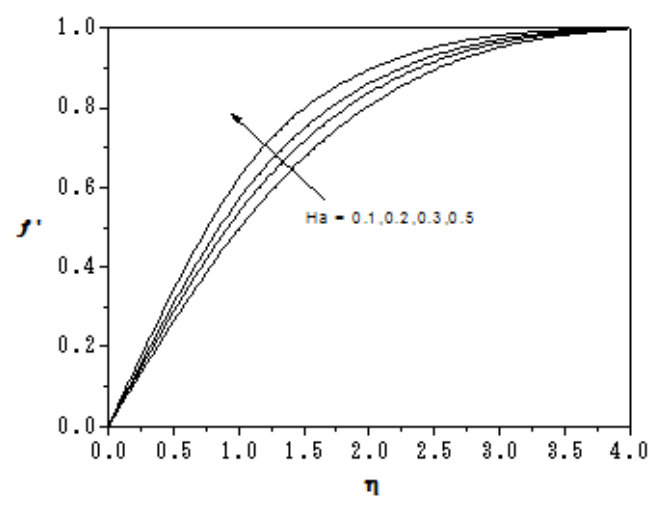

Fig.1: Variation of the velocity component $f^{\prime}$ with $\mathrm{Ha}$ for $\mathrm{Pr}=0.72, \mathrm{Sc}=0.62, \mathrm{Gr}=\mathrm{Gc}=\mathrm{Bi}=0.1, \mathrm{Kr}=0.5, \mathrm{Du}=0.2, \mathrm{Sr}=1.0, \mathrm{Ec}=0.01$.

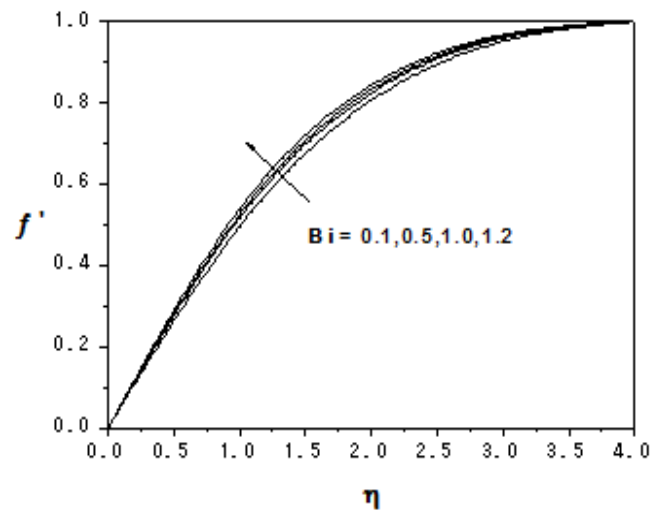

Fig.2: Variationof the velocity component $f^{\prime}$ with $B i$ for $\mathrm{Pr}=0.72, \mathrm{Sc}=0.62, \mathrm{Gr}=\mathrm{Gc}=\mathrm{Ha}=0.1, \mathrm{Kr}=0.5, \mathrm{Du}=0.2, \mathrm{Sr}=1.0, \mathrm{Ec}=0.01$.

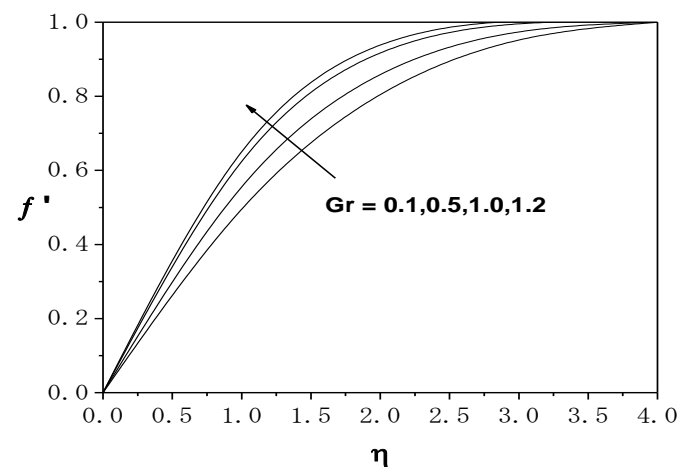

Fig.3: Variation of the velocity component $f^{\prime}$ with $G r$ for $\mathrm{Pr}=0.72, \mathrm{Sc}=0.62, \mathrm{Gc}=\mathrm{Ha}=\mathrm{Bi}=0.1, \mathrm{Kr}=0.5, \mathrm{Du}=0.2, \mathrm{Sr}=1.0, \mathrm{Ec}=0.01$. 


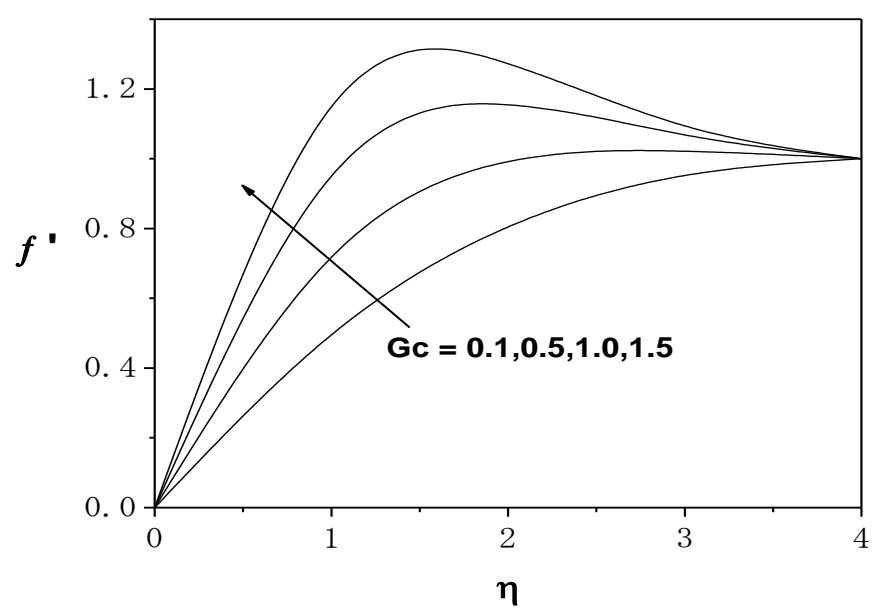

Fig.4: Variation of the velocity component $f^{\prime}$ with Gc for $\operatorname{Pr}=0.72, \mathrm{Sc}=0.62, \mathrm{Gr}=\mathrm{Ha}=\mathrm{Bi}=0.1, \mathrm{Kr}=0.5, \mathrm{Du}=0.2, \mathrm{Sr}=1.0, \mathrm{Ec}=0.01$.

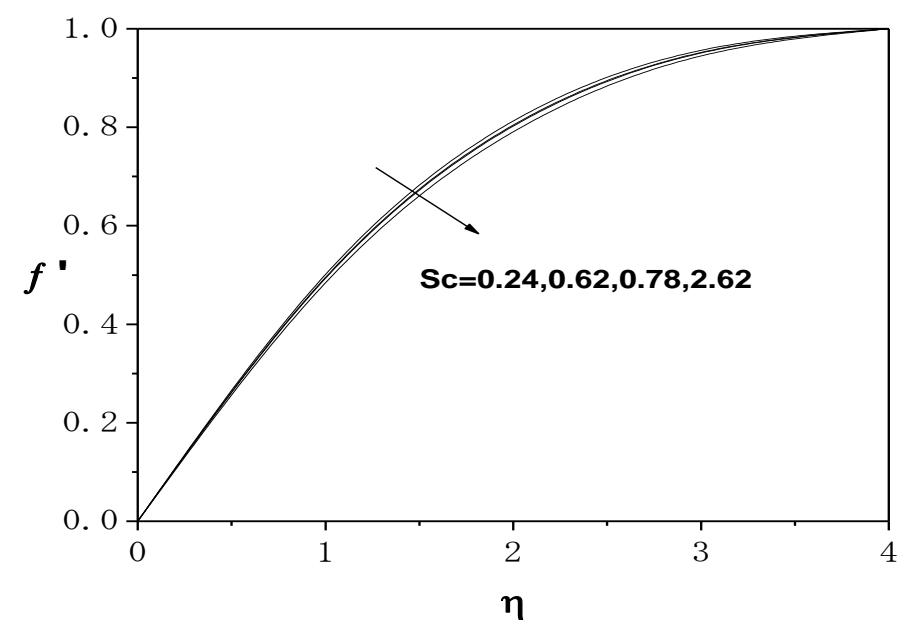

Fig.5: Variation of the velocity with $\mathrm{Sc}$ for $\mathrm{Pr}=0.72, \mathrm{Gr}=\mathrm{Gc}=\mathrm{Ha}=\mathrm{Bi}=0.1, \mathrm{Kr}=0.5, \mathrm{Du}=0.2, \mathrm{Sr}=1.0, \mathrm{Ec}=0.01$

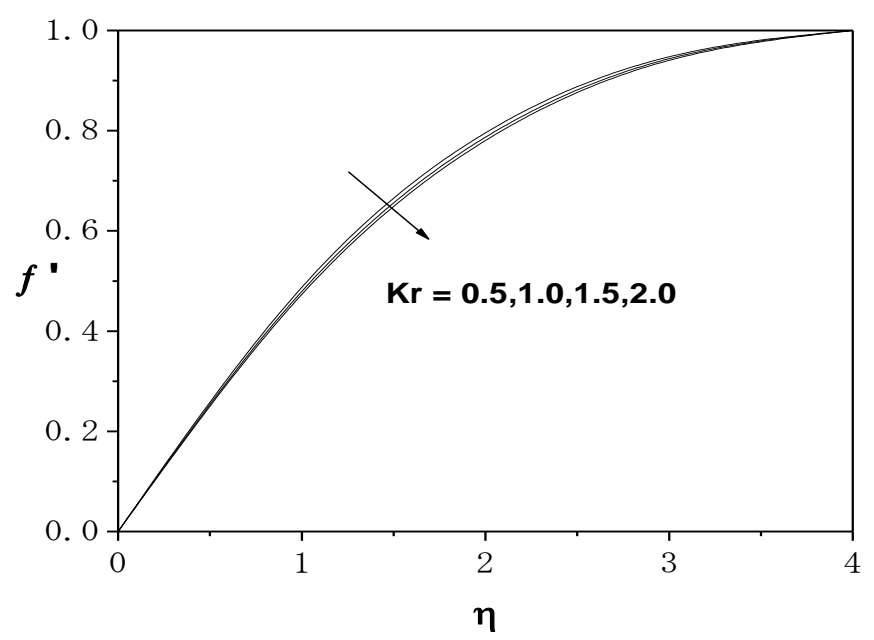

Fig .6: Variation of the velocity component $f^{\prime}$ with $K r$ for $\mathrm{Pr}=0.72, \mathrm{Sc}=0.62, \mathrm{Gr}=\mathrm{Gc}=\mathrm{Ha}=\mathrm{Bi}=0.1, \mathrm{Du}=0.2, \mathrm{Sr}=1.0, \mathrm{Ec}=0.01$. 


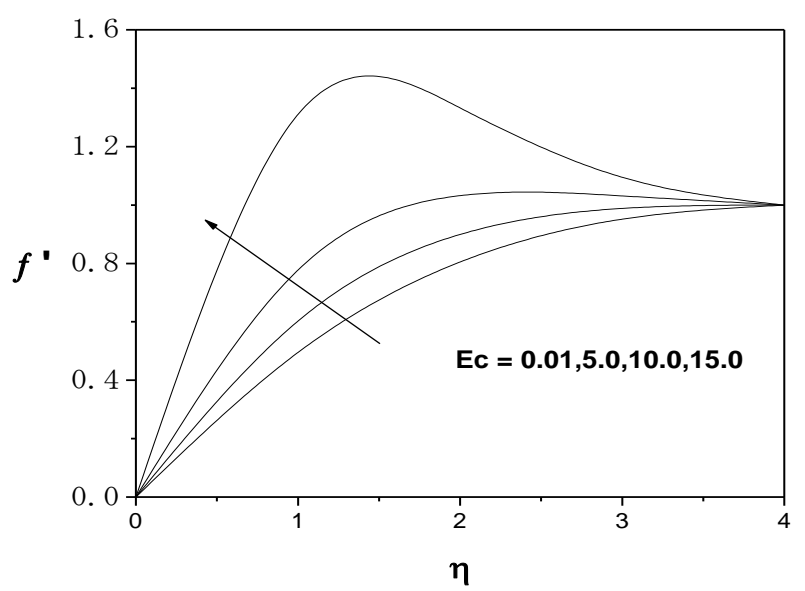

Fig.7: Variation of the velocity component $f^{\prime}$ with $E c$ for $\mathrm{Pr}=0.72, \mathrm{Sc}=0.62, \mathrm{Gr}=\mathrm{Gc}=\mathrm{Ha}=\mathrm{Bi}=0.1, \mathrm{Kr}=0.5, \mathrm{Du}=0.2, \mathrm{Sr}=1$

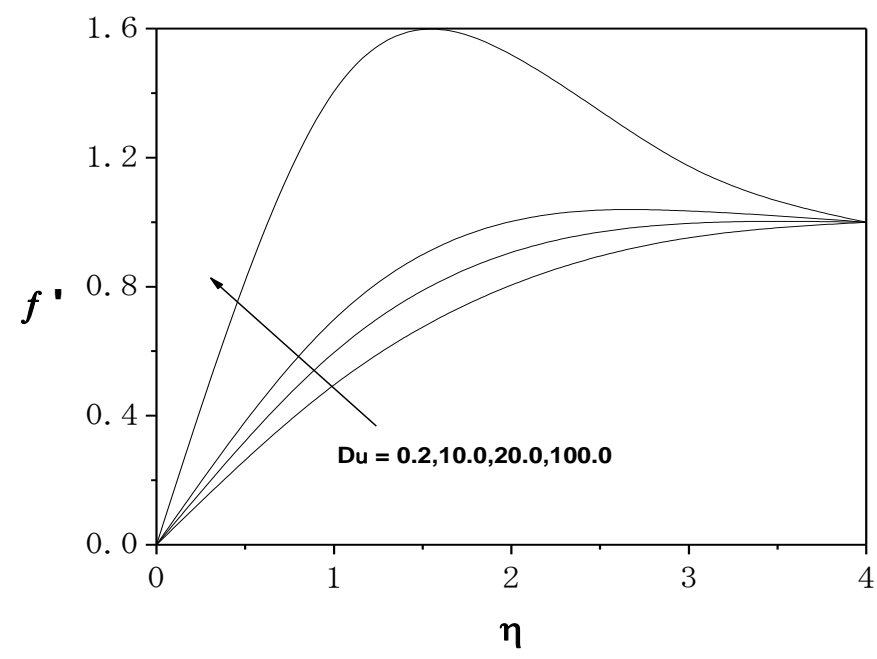

Fig.8: Variation of the velocity component $f^{\prime}$ with $D u$ for $\mathrm{Pr}=0.72, \mathrm{Sc}=0.62, \mathrm{Gr}=\mathrm{Gc}=\mathrm{Ha}=\mathrm{Bi}=0.1, \mathrm{Kr}=0.5, \mathrm{Sr}=1.0, \mathrm{Ec}=0.01$

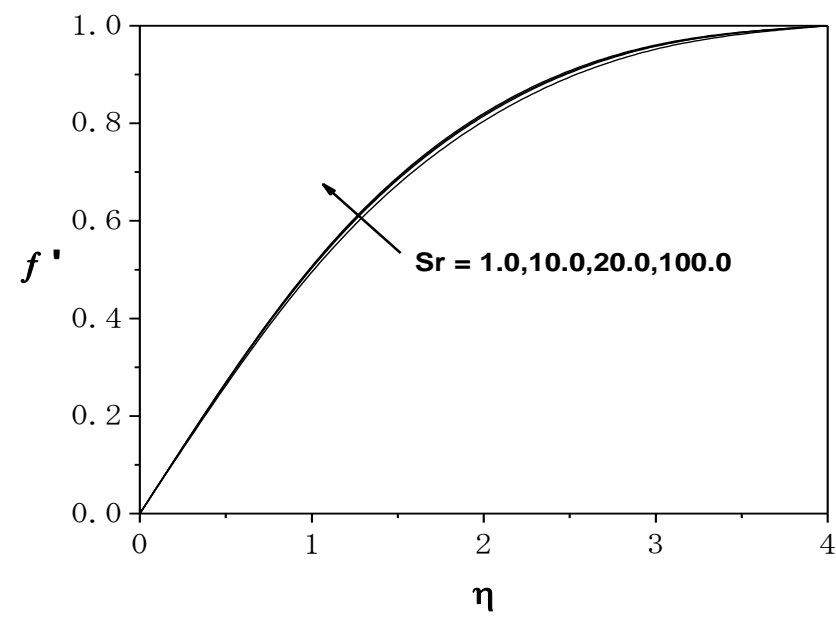

Fig.9: Variation of the velocity component $f^{\prime}$ with $S r$ for $\mathrm{Pr}=0.72, \mathrm{Sc}=0.62, \mathrm{Gr}=\mathrm{Gc}=\mathrm{Ha}=\mathrm{Bi}=0.1, \mathrm{Kr}=0.5, \mathrm{Du}=0.2, \mathrm{Ec}=0.01$. 


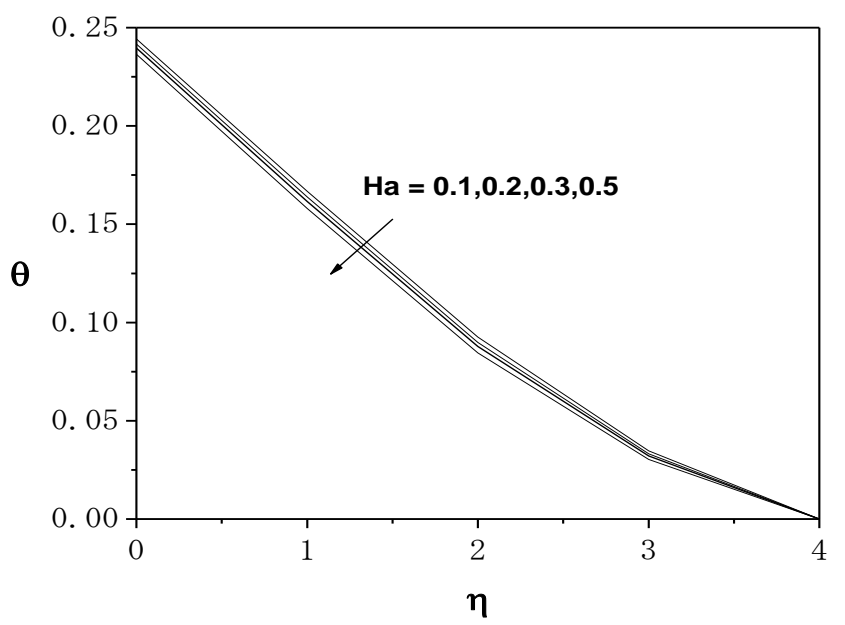

Fig.10: Variation of the temperature $\theta$ with $\mathrm{Ha}$ for $\operatorname{Pr}=0.72, \mathrm{Sc}=0.62, \mathrm{Gr}=\mathrm{Bi}=\mathrm{Gc}=0.1, \mathrm{Kr}=0.5, \mathrm{Du}=0.2, \mathrm{Sr}=1.0, \mathrm{Ec}=0.01$

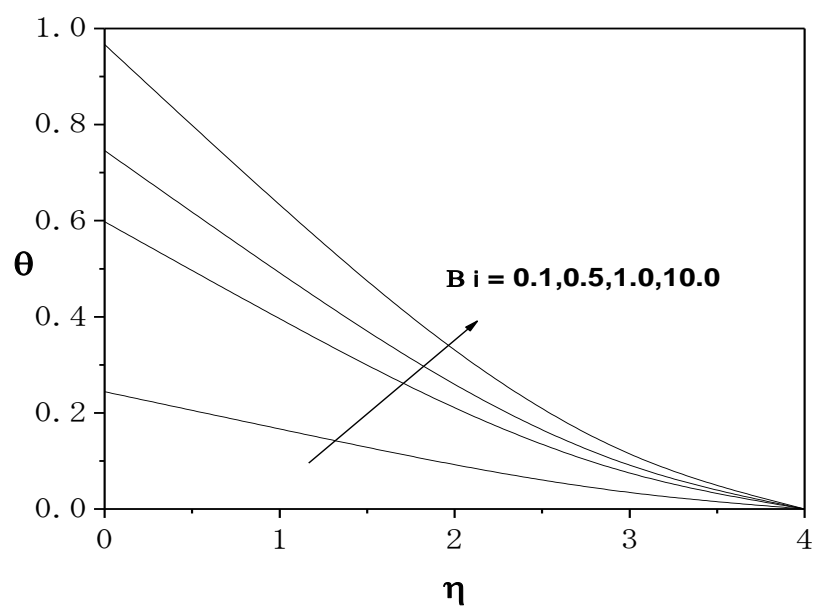

Fig.11: Variation of the temperature $\theta$ with $B i$ for $\mathrm{Pr}=0.72, \mathrm{Sc}=0.62, \mathrm{Gr}=\mathrm{Gc}=\mathrm{Ha}=0.1, \mathrm{Kr}=0.5, \mathrm{Du}=0.2, \mathrm{Sr}=1.0, \mathrm{Ec}=0.01$

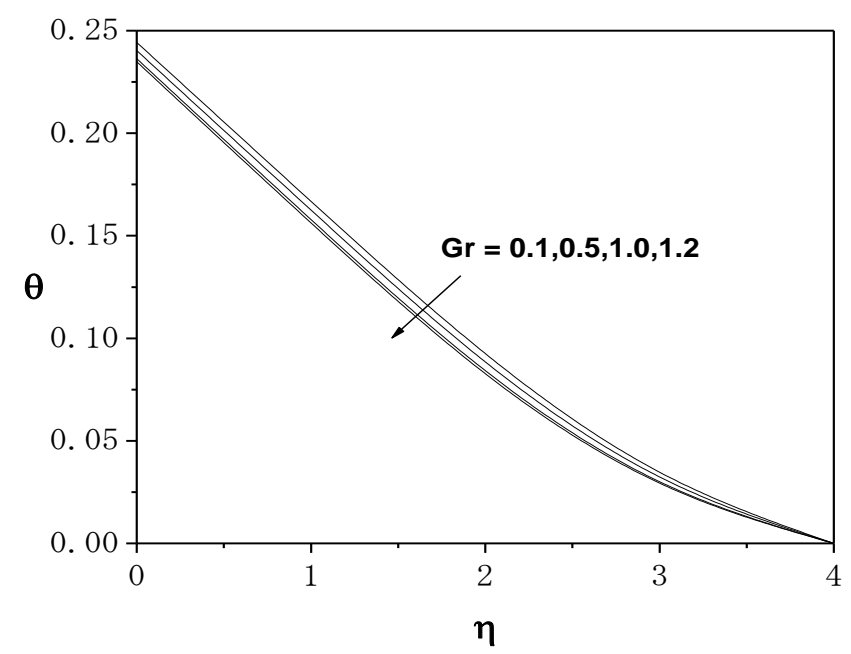

Fig.12: Variation of the temperature $\theta$ with $G r$ for $\mathrm{Pr}=0.72, \mathrm{Sc}=0.62, \mathrm{Gc}=\mathrm{Bi}=\mathrm{Ha}=0.1, \mathrm{Kr}=0.5, \mathrm{Du}=0.2, \mathrm{Sr}=1.0, \mathrm{Ec}=0.01$. 


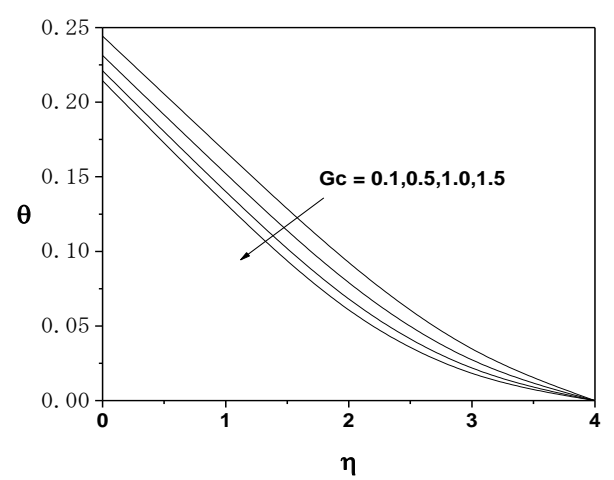

Fig.13: Variation of the temperature $\theta$ with $G c$ for $\mathrm{Pr}=0.72, \mathrm{Sc}=0.62, \mathrm{Gr}=\mathrm{Bi}=\mathrm{Ha}=0.1, \mathrm{Kr}=0.5, \mathrm{Du}=0.2, \mathrm{Sr}=1.0, \mathrm{Ec}=0.01$

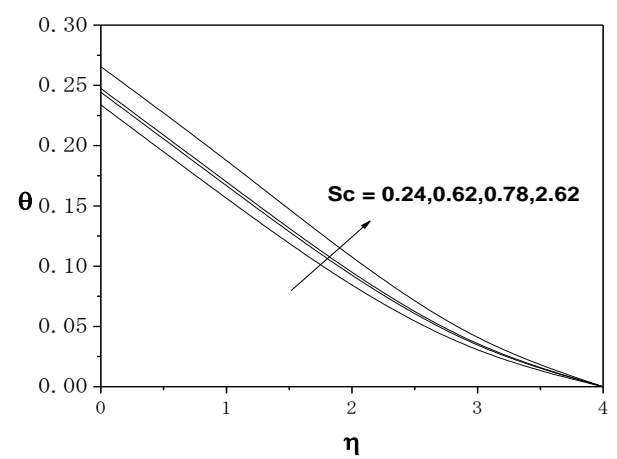

Fig.14: Variation of the temperature $\theta$ with $S c$ for $\operatorname{Pr}=0.72, \mathrm{Gr}=\mathrm{Bi}=\mathrm{Gc}=\mathrm{Ha}=0.1, \mathrm{Kr}=0.5, \mathrm{Du}=0.2, \mathrm{Sr}=1.0, \mathrm{Ec}=0.01$

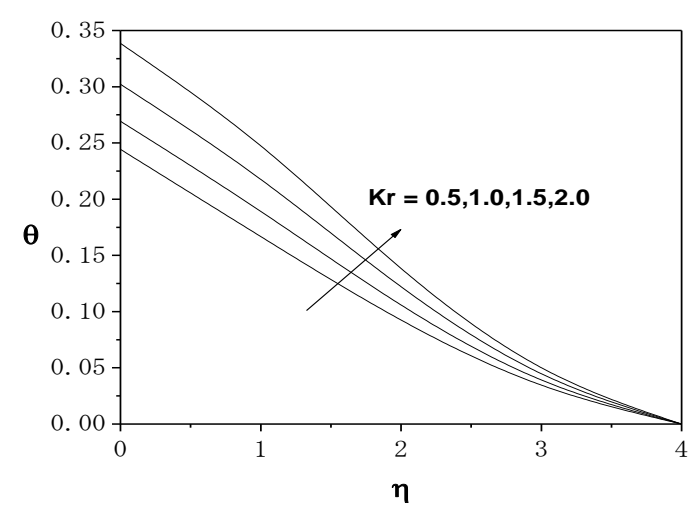

Fig.15: Variation of the temperature $\theta$ with $K r$ for $\mathrm{Pr}=0.72, \mathrm{Sc}=0.62, \mathrm{Gr}=\mathrm{Bi}=\mathrm{Ha}=\mathrm{Bi}=0.1, \mathrm{Du}=0.2, \mathrm{Sr}=1.0, \mathrm{Ec}=0.01$

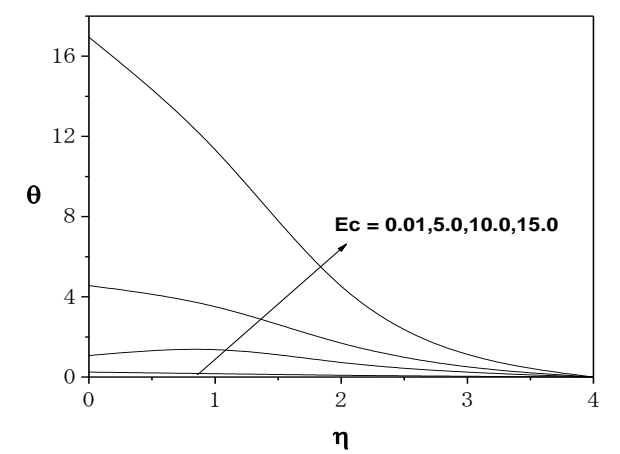

Fig.16: Variation of the temperature $\theta$ with $E c$ for $\mathrm{Pr}=0.72, \mathrm{Sc}=0.62, \mathrm{Gr}=\mathrm{Bi}=\mathrm{Ha}=\mathrm{Gc}=0.1, \mathrm{Kr}=0.5, \mathrm{Du}=0.2, \mathrm{Sr}=1.0$ 


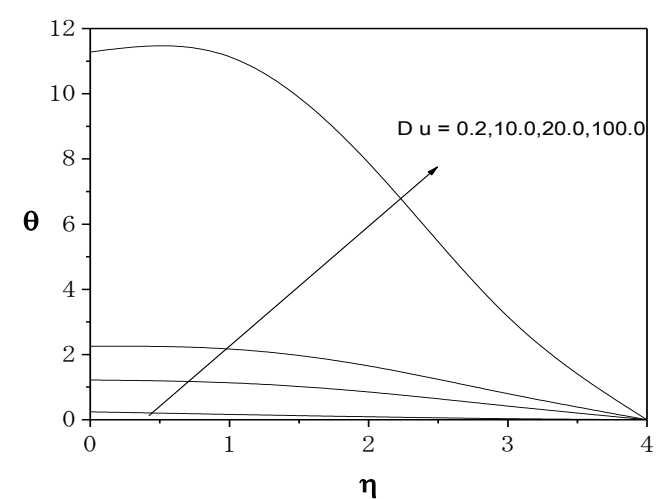

Fig.17: Variation of the temperature $\theta$ with $G c$ for $\mathrm{Pr}=0.72, \mathrm{Sc}=0.62, \mathrm{Gr}=\mathrm{Bi}=\mathrm{Ha}=0.1, \mathrm{Kr}=0.5, \mathrm{Sr}=1.0, \mathrm{Ec}=0.01$

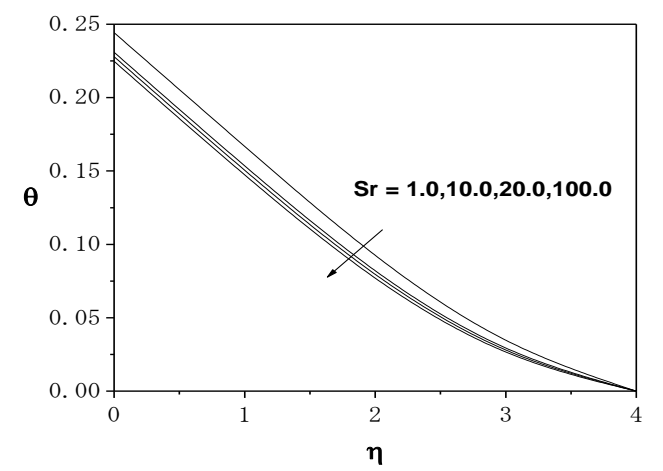

Fig.18: Variation of the temperature $\theta$ with $\mathrm{Sr}$ for $\mathrm{Pr}=0.72, \mathrm{Sc}=0.62, \mathrm{Gr}=\mathrm{Bi}=\mathrm{Gc}=\mathrm{Ha}=0.1, \mathrm{Kr}=0.5, \mathrm{Du}=0.2, \mathrm{Sr}=1.0, \mathrm{Ec}=0.01$.

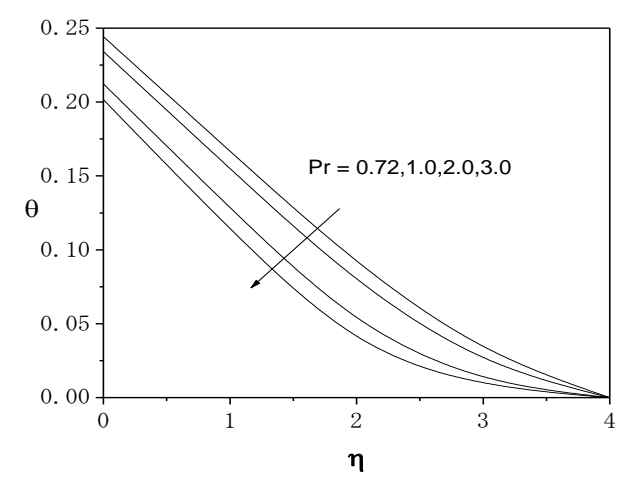

Fig.19: Variation of the temperature $\theta$ with $\operatorname{Pr}$ for $\mathrm{Sc}=0.62, \mathrm{Gr}=\mathrm{Bi}=\mathrm{Ha}=\mathrm{Gc}=0.1, \mathrm{Kr}=0.5, \mathrm{Du}=0.2, \mathrm{Sr}=1.0, \mathrm{Ec}=0.01$.

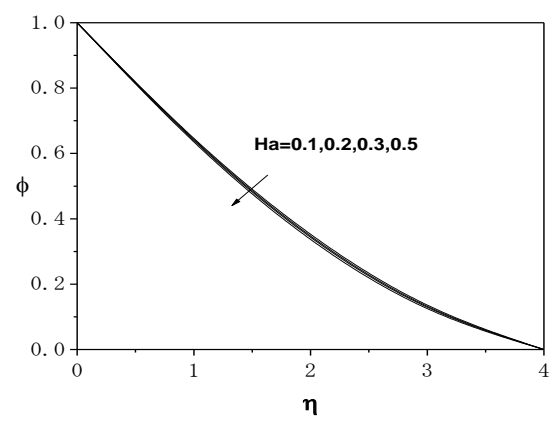

Fig.20: Variation of the concentration $\phi$ with $H a$ for

$\mathrm{Pr}=0.72, \mathrm{Sc}=0.62, \mathrm{Gr}=\mathrm{Gc}=\mathrm{Bi}=0.1, \mathrm{Kr}=0.5, \mathrm{Du}=0.2, \mathrm{Sr}=1.0, \mathrm{Ec}=0.01$ 


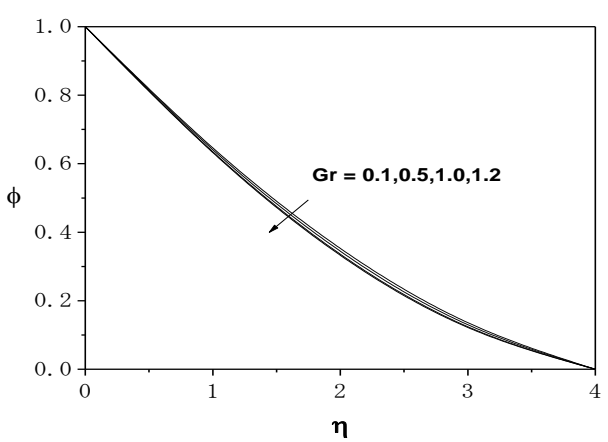

Fig.21: Variation of the concentration $\phi$ with $G r$ for $\mathrm{Pr}=0.72, \mathrm{Sc}=0.62, \mathrm{Ha}=\mathrm{Gc}=\mathrm{Bi}=0.1, \mathrm{Kr}=0.5, \mathrm{Du}=0.2, \mathrm{Sr}=1.0, \mathrm{Ec}=0.01$

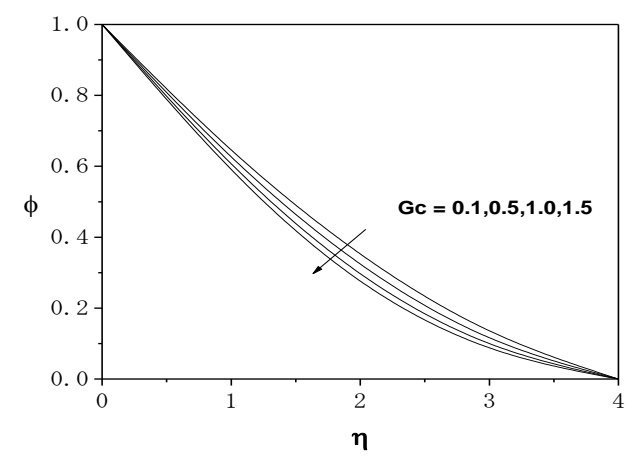

Fig.22: Variation of the concentration $\phi$ with $G c$ for $\operatorname{Pr}=0.72, \mathrm{Sc}=0.62, \mathrm{Gr}=\mathrm{Ha}=\mathrm{Bi}=0.1, \mathrm{Kr}=0.5, \mathrm{Du}=0.2, \mathrm{Sr}=1.0, \mathrm{Ec}=0.01$

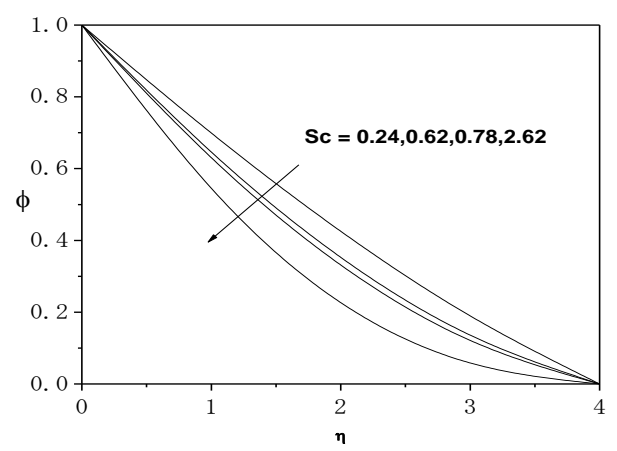

Fig.23: Variation of the concentration $\phi$ with $S c$ for $\mathrm{Pr}=0.72, \mathrm{Kr}=0.5, \mathrm{Gr}=\mathrm{Gc}=\mathrm{Ha}=\mathrm{Bi}=0.1, \mathrm{Du}=0.2, \mathrm{Sr}=1.0, \mathrm{Ec}=0.01$.

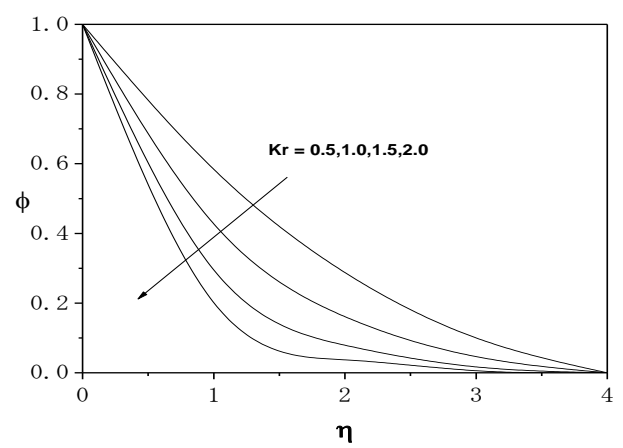

Fig.24: Variation of the concentration $\phi$ with $K r$ for $\mathrm{Pr}=0.72, \mathrm{Du}=0.2, \mathrm{Sc}=0.62, \mathrm{Gr}=\mathrm{Gc}=\mathrm{Bi}=\mathrm{Ha}=0.1, \mathrm{Sr}=1.0, \mathrm{Ec}=0.01$. 


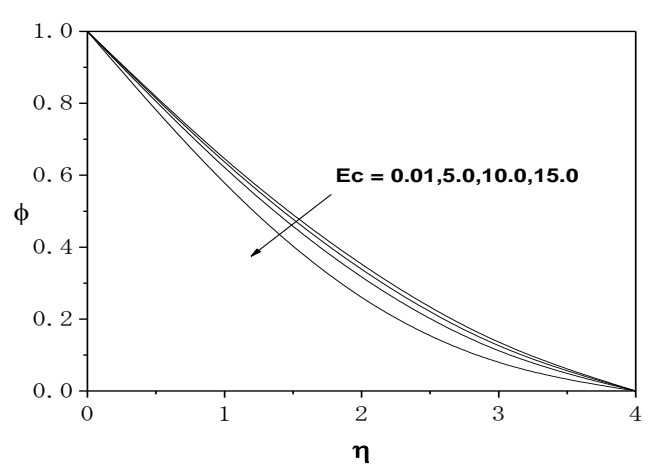

Fig.25: Variation of the concentration $\phi$ with $E c$ for

$\operatorname{Pr}=0.72, \mathrm{Kr}=0.5, \mathrm{Sc}=0.62, \mathrm{Gr}=\mathrm{Gc}=\mathrm{Bi}=\mathrm{Ha}=0.1, \mathrm{Du}=0.2, \mathrm{Sr}=1.0$.

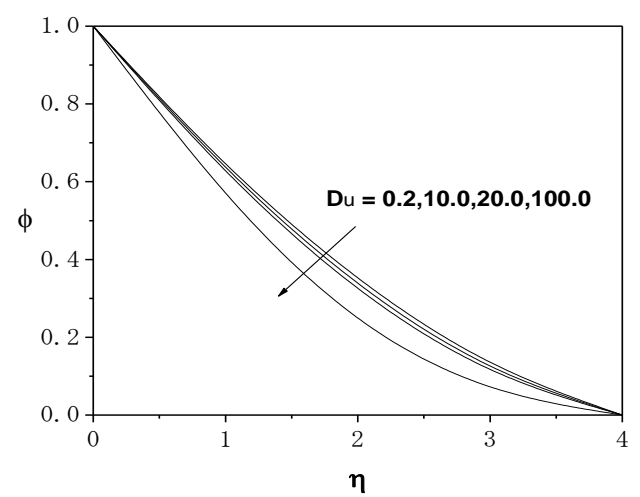

Fig.26: Variation of the concentration $\phi$ with $D u$ for $\mathrm{Pr}=0.72, \mathrm{Kr}=0.5, \mathrm{Sc}=0.62, \mathrm{Gr}=\mathrm{Gc}=\mathrm{Bi}=\mathrm{Ha}=0.1, \mathrm{Sr}=1.0, \mathrm{Ec}=0.01$.

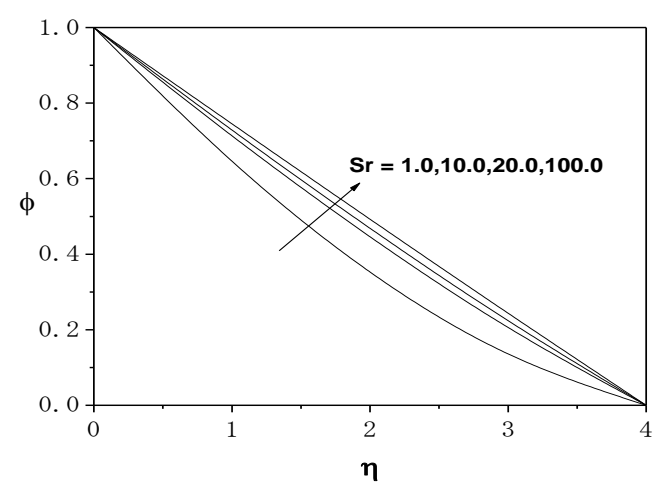

Fig.27: Variation of the concentration $\phi$ with $S r$ for

$\mathrm{Pr}=0.72, \mathrm{Sc}=0.62, \mathrm{Gr}=\mathrm{Gc}=\mathrm{Bi}=\mathrm{Ha}=0.1, \mathrm{Kr}=0.5, \mathrm{Du}=0.2, \mathrm{Ec}=0.01$.

\section{Conclusions}

We have studied hydromagnetic mixed convection heat and mass transfer over a vertical plate subjected to convective heat exchange with the surrounding in the presence of magnetic field and chemical reaction. The governing equations are approximated to a system of non-linear ordinary differential equations by similarity transformation. Numerical calculations are carried out for various values of the dimensionless parameters of the problem. A comparison with previously published work is performed and excellent agreement between the results is obtained. The results are presented graphically and the conclusions are drawn that the flow field and other quantities of physical interest are significantly influenced by these parameters. The results for the prescribed skin friction, local heat and mass transfer rate at the plate surface are presented and discussed. It was found that the local skin-friction coefficient, local heat and mass transfer rate at the plate surface 
increases with an increase in intensity of magnetic field, buoyancy forces, convective heat exchange parameter, Soret number, Eckert number, Dufour number and chemical reaction parameter.

Table 1 Variation of $C_{f}, N u, S h$ at the plate for $\operatorname{Pr}=0.71$

\begin{tabular}{|l|l|l|l|l|l|l|l|l|l|l|l|}
\hline$B i$ & $G r$ & $G c$ & $H a$ & $\mathrm{Sc}$ & $\mathrm{Sr}$ & $K r$ & $\mathrm{Du}$ & $\mathrm{Ec}$ & $C_{f}$ & $\mathrm{Nu}$ & $\mathrm{Sh}$ \\
& & & & & & & & & & & \\
\hline 0.1 & 0.1 & 0.1 & 0.1 & 0.62 & 1 & 0.5 & 0.2 & 0.01 & 0.596611 & 0.075537 & 0.381552 \\
\hline 1 & 0.1 & 0.1 & 0.1 & 0.62 & 1 & 0.5 & 0.2 & 0.01 & 0.649006 & 0.253486 & 0.384407 \\
\hline 10 & 0.1 & 0.1 & 0.1 & 0.62 & 1 & 0.5 & 0.2 & 0.01 & 0.671671 & 0.332795 & 0.385626 \\
\hline 0.1 & 0.5 & 0.1 & 0.1 & 0.62 & 1 & 0.5 & 0.2 & 0.01 & 0.700125 & 0.075922 & 0.387268 \\
\hline 0.1 & 1 & 0.1 & 0.1 & 0.62 & 1 & 0.5 & 0.2 & 0.01 & 0.821246 & 0.076328 & 0.393721 \\
\hline 0.1 & 0.1 & 0.5 & 0.1 & 0.62 & 1 & 0.5 & 0.2 & 0.01 & 0.994141 & 0.076825 & 0.402332 \\
\hline 0.1 & 0.1 & 1 & 0.1 & 0.62 & 1 & 0.5 & 0.2 & 0.01 & 1.444536 & 0.077844 & 0.423352 \\
\hline 0.1 & 0.1 & 0.1 & 0.4 & 0.62 & 1 & 0.5 & 0.2 & 0.01 & 0.813629 & 0.076167 & 0.391165 \\
\hline 0.1 & 0.1 & 0.1 & 0.6 & 0.62 & 1 & 0.5 & 0.2 & 0.01 & 0.930447 & 0.076430 & 0.395548 \\
\hline 0.1 & 0.1 & 0.1 & 0.1 & 0.78 & 1 & 0.5 & 0.2 & 0.01 & 0.594611 & 0.075216 & 0.402517 \\
\hline 0.1 & 0.1 & 0.1 & 0.1 & 2.62 & 1 & 0.5 & 0.2 & 0.01 & 0.584549 & 0.073423 & 0.520237 \\
\hline 0.1 & 0.1 & 0.1 & 0.1 & 0.62 & 2 & 0.5 & 0.2 & 0.01 & 0.598834 & 0.075883 & 0.358936 \\
\hline 0.1 & 0.1 & 0.1 & 0.1 & 0.62 & 3 & 0.5 & 0.2 & 0.01 & 0.600445 & 0.076128 & 0.342961 \\
\hline 0.1 & 0.1 & 0.1 & 0.1 & 0.62 & 1 & 1 & 0.2 & 0.01 & 0.588073 & 0.073054 & 0.544738 \\
\hline 0.1 & 0.1 & 0.1 & 0.1 & 0.62 & 1 & 1.5 & 0.2 & 0.01 & 0.579232 & 0.069785 & 0.757191 \\
\hline 0.1 & 0.1 & 0.1 & 0.1 & 0.62 & 1 & 0.5 & 0.4 & 0.01 & 0.599633 & 0.073623 & 0.381748 \\
\hline 0.1 & 0.1 & 0.1 & 0.1 & 0.62 & 1 & 0.5 & 0.6 & 0.01 & 0.602658 & 0.071702 & 0.381944 \\
\hline 0.1 & 0.1 & 0.1 & 0.1 & 0.62 & 1 & 0.5 & 0.2 & 0.02 & 0.596901 & 0.075318 & 0.381569 \\
\hline 0.1 & 0.1 & 0.1 & 0.1 & 0.62 & 1 & 0.5 & 0.2 & 0.03 & 0.597481 & 0.074882 & 0.381603 \\
\hline
\end{tabular}

Table 2 computations showing comparison with Gnaneswar Reddy \& Bhaskar Reddy [6] results for Numerical values of the skin-friction coefficient $C_{f}$, Nusselt number $N u$ and Sherwood number $S h$ for

$$
G r=2.0, G c=2.0, H a=0.5, K r=0.5, B i=0.5 \text {. }
$$

\begin{tabular}{|c|c|c|c|c|c|c|c|c|c|c|}
\hline \multirow[t]{2}{*}{ Pr } & \multirow[t]{2}{*}{$\mathrm{EC}$} & \multirow[t]{2}{*}{$\mathrm{Du}$} & \multirow[t]{2}{*}{$\mathrm{Sc}$} & \multirow[t]{2}{*}{$\mathrm{Sr}$} & \multicolumn{3}{|l|}{$\begin{array}{l}\text { Previous } \\
\text { work [6] }\end{array}$} & \multicolumn{3}{|l|}{$\begin{array}{l}\text { Present } \\
\text { work }\end{array}$} \\
\hline & & & & & $C_{\mathrm{f}}$ & $\mathrm{Nu}$ & Sh & $C_{\mathrm{f}}$ & $\mathrm{Nu}$ & Sh \\
\hline 0.71 & 0.01 & 0.2 & 0.6 & 1 & 0.823025 & 0.861862 & 0.436223 & 0.974969 & 0.838996 & 0.418769 \\
\hline 1 & 0.01 & 0.2 & 0.6 & 1 & 0.753718 & 1.108723 & 0.290841 & 0.902458 & 0.953311 & 0.414998 \\
\hline 0.71 & 0.02 & 0.2 & 0.6 & 1 & 0.824066 & 0.859063 & 0.437788 & 0.988814 & 0.834385 & 0.419263 \\
\hline 0.71 & 0.01 & 0.4 & 0.6 & 1 & 0.840539 & 0.829245 & 0.457354 & 0.998980 & 0.834253 & 0.420044 \\
\hline 0.71 & 0.01 & 0.2 & 0.78 & 1 & 0.773150 & 0.846942 & 0.499496 & 0.939987 & 0.837364 & 0.447626 \\
\hline 0.71 & 0.01 & 0.2 & 0.6 & 2 & 1.008445 & 0.933033 & 0.293132 & 1.009144 & 0.840535 & 0.391731 \\
\hline
\end{tabular}

\section{References}

[1]. Alam M. S., Rahman M. M., Samad M.A. Dufour and Soret Effects on Unsteady MHD Free Convection and Mass Transfer Flow past a Vertical Porous Plate in a Porous Medium, Nonlinear Analysis: Modelling and Control, 2006, Vol. 11, No. 3, $217-226$

[2]. Anghel M, Takhar HS, and Pop I (2000). Dufour and Soret effects on free convection boundary layer over a vertical surface embedded in a porous medium. J. Heat and Mass Transfer, 43, pp. 1265-1274.

[3]. Bejan A and Khair KR (1985). Heat and mass transfer by natural convection in a porous medium. Int. J. Heat Mass Transfer, 28, pp. 909-918.

[4]. Dursunkaya $\mathrm{Z}$ and Worek WM (1992). Diffusion-thermo and thermal diffusion effects in transient and steady natural convection from a vertical surface. Int. J. Heat Mass Transfer, 35, pp. 2060-2065.

[5]. Eckert ERG and Drake RM (1972). Analysis of Heat and Mass Transfer. McGraw-Hill Book Co., New York.

[6]. Gnaneswar Reddy.M., and Bhaskar Reddy.N.,(2010). Soret and Dufour effects on steady MHD free convection flow past a semiinfinite moving vertical plate in a porous medium with viscous dissipationInt J.of Appl.Math and Meth.6(1):1-12.

[7]. Jain MK, Iyengar SRK, and Jain RK (1985). Numerical Methods for Scientific and Engineering Computation. Wiley Eastern Ltd., New Delhi, India.

[8]. Kafoussias NG and Williams EM (1995). Thermal-diffusion and Diffusion-thermo effects on free convective and mass transfer boundary layer flow with temperature dependent viscosity. Int. J. Eng. Science, 33, pp.1369-1376.

[9]. Lai FC and Kulacki FA (1990). Coupled heat and mass transfer from a sphere buried in an infinite porous medium. Int. J. Heat Mass Transfer, 33, pp.209-215.

[10]. Lai FC and Kulacki FA (1991). Coupled heat and mass transfer by natural convection from vertical surfaces in a porous medium. Int. J Heat Mass Transfer, 34, pp.1189-1194.

[11]. Makinde O.D., (2010). Similarity solution of hydromagnetic heat and mass transfer over a vertical plate with a convective surface boundary condition. Int .J.Phy.Sci. 5(6),pp.700-710. 
[12]. Makinde O.D.,\& Ogulu A.,(2008). The effect of thermal radiation on the heat and mass transfer flow of a variable viscosity fluid past a vertical porous plate permeated by a transverse magnetic field, Chem.Eng.Commun.195(12):1575-1584.

[13]. Maleque .Kh. A., Dufour and Soret effects on unsteady MHD Convective Heat and Mass Transfer Flow due to a Rotating Disk, Latin American Applied Research, 40:105-111 (2010)

[14]. Postelnicu A (2004). Influence of a magnetic field on heat and mass transfer by natural convection from vertical surfaces in porous media considering Soret and Dufour effects. Int. J. Heat Mass Transfer, 47, pp.1467-1472.

[15]. Raptis A, Tzivanidis G, and Kafousias N (1981). Free convection and mass transfer flow through a porous medium bounded by an infinite vertical limiting surface with constant suction. Lett. Heat Mass Transfer, 8, pp. 417-424.

[16]. Shariful Alam. Md., Rahman. M. M., Abdul Maleque. Md., Local Similarity Solutions for Unsteady MHD free Convection and Mass Transfer Flow Past an Impulsively Started Vertical Porous Plate with Dufour and Soret Effects, ThammasaItn t. J. Sc.T ech.,V ol. 10,N o. 3, July-Septembe 2005

\section{Nomenclature}

$\mathrm{Ha} \quad$ Magnetic field parameter

Gr Thermal Grashof number

Gc Solutal Grashof number

$\mathrm{Du} \quad$ Dufour number

Sr Soret number

Ec Eckert number

Bi Convective heat transfer parameter

Pr Prandtl number

Sc Schmidt number

$\mathrm{Kr}^{2} \quad$ Chemical reaction rate constant

Re Reynolds number

$u, v \quad$ velocity components along $\mathrm{x}$-and $\mathrm{y}$ - axes respectively

$x, y \quad$ Cartesian coordinates along $\mathrm{x}-, \mathrm{y}$-axes respectively

$\mathrm{T} \quad$ fluid temperature

C fluid concentration

$\kappa \quad$ the thermal conductivity

$D_{m} \quad$ mass diffusivity

$B_{0} \quad$ Magnetic induction

g gravitational acceleration

$C_{\infty} \quad$ free stream concentration

$K^{\prime} \quad$ permeability of the porous medium

$f \quad$ dimensionless stream function

$C_{f} \quad$ skin-friction coefficient

h plate heat transfer coefficient

$L \quad$ plate characteristic length

$C_{w} \quad$ species concentration at the plate surface

\section{Greek Letters}

$\begin{array}{ll}v & \text { kinematics viscosity } \\ \rho & \text { density } \\ \sigma & \text { Electric conductivity } \\ \beta_{T} & \text { Thermal expansions } \\ \beta_{c} & \text { Concentration } \\ \alpha & \text { Thermal diffusivity } \\ \theta- & \text { Dimensionless temperature }\left\{=\left(T-T_{\infty}\right) /\left(T_{w}-T_{\infty}\right)\right\} \\ \phi & \text { Dimensionless concentration }\left\{=\left(C-C_{\infty}\right) /\left(C_{w}-C_{\infty}\right)\right\} \\ \eta & \text { Similarity variable } \\ \psi & \text { Stream function } \\ \lambda & \text { plate surface concentration exponent }\end{array}$

